\title{
Secular variations in helium isotope ratios in Izu Oshima volcano
}

\author{
HIROCHIKA SUMINO ${ }^{1}$, KEI IKEHATA ${ }^{2}$, AYA SHIMIZU ${ }^{3}$, \\ KOTARO TOYAMA ${ }^{4}$, DR. TOMOYA OBASE, PHD ${ }^{1}$ AND \\ KENJI NOTSU ${ }^{1}$ \\ ${ }^{1}$ The University of Tokyo \\ ${ }^{2}$ University of Tsukuba \\ ${ }^{3}$ Tokyo Metropolitan Industrial Technology Research Institute \\ ${ }^{4}$ Atmosphere and Ocean Research Institute, The University of \\ Tokyo \\ Presenting Author: sumino@igcl.c.u-tokyo.ac.jp
}

Helium isotope ratios $\left({ }^{3} \mathrm{He} /{ }^{4} \mathrm{He}\right)$ differ significantly in geochemical reservoirs such as air, the crust, and the mantle. Therefore, helium in volcanic gases can be used as a sensitive tracer of magma activity. In Izu-Oshima volcano, ${ }^{3} \mathrm{He} /{ }^{4} \mathrm{He}$ of a steam well increased immediately after the 1986 eruption from a low value of $1.7 \mathrm{Ra}$, peaked in 1988 at $5.5 \mathrm{Ra}$, and has been decreasing until now (Sano et al., EPSL 1991). The ${ }^{3} \mathrm{He} /{ }^{4} \mathrm{He}$ corrected for atmospheric contamination using ${ }^{4} \mathrm{He} /{ }^{20} \mathrm{Ne}$ was about 6.2 Ra throughout the last 1986-1990 eruptive activity. On the other hand, air-corrected ${ }^{3} \mathrm{He} /{ }^{4} \mathrm{He}$ of hot spring gases collected from other wells have been constant at $6.2 \mathrm{Ra}$ since 2001. These results suggest that the supply of magma-derived helium to the steam well has been decreasing, while the ${ }^{3} \mathrm{He} /{ }^{4} \mathrm{He}$ of magmatic gas itself has been constant over the past 30 years.

The lower ${ }^{3} \mathrm{He} /{ }^{4} \mathrm{He}$ of the present magma than the mantle value of $8 \mathrm{Ra}$ suggests the significant contribution of crustal helium in the magma reservoir. On the other hand, ${ }^{3} \mathrm{He} /{ }^{4} \mathrm{He}$ of olivines in 19-40 ka volcanic rocks are around $7 \mathrm{Ra}$, suggesting that ${ }^{3} \mathrm{He} /{ }^{4} \mathrm{He}$ of the magma at these stages were more similar to that of the mantle. However, ${ }^{3} \mathrm{He} /{ }^{4} \mathrm{He}$ of olivines in $1.3 \mathrm{ka}$ scoria is $4.6 \mathrm{Ra}$, indicating that crustal helium significantly contaminated the magma.

Based on these observations, two scenarios can be expected for the next eruption: first, if the old magma reservoir is reactivated, the ${ }^{3} \mathrm{He} /{ }^{4} \mathrm{He}$ of hot spring gases will remain unchanged at about $6 \mathrm{Ra}$, and only the contribution of magmaderived helium in the steam well will increase, similarly to the previous eruptive activity. In the second scenario, in which the reactivation of the magma is caused by a supply of primitive magma with a high ${ }^{3} \mathrm{He} /{ }^{4} \mathrm{He}$, not only the contribution of magmatic helium in the steam well increases, but also the aircorrected ${ }^{3} \mathrm{He} /{ }^{4} \mathrm{He}$ of the steam and hot-spring gases will be higher than $6 \mathrm{Ra}$. Namely, whether the next eruption results from new magma supply from greater depths or just reactivation of the old magma can be constrained by ${ }^{3} \mathrm{He} /{ }^{4} \mathrm{He}$. 